\title{
Postnatal changes in maternal and neonatal plasma antioxidant vitamins and the influence of smoking
}

\author{
S Bolisetty, D Naidoo, K Lui, T H H G Koh, D Watson, R Montgomery, J Whitehall
}

Arch Dis Child Fetal Neonatal Ed 2002;86:F36-F40

See end of article for authors' affiliations

\section{Correspondence to}

Dr Bolisetty, Alice Springs

Hospital, PO Box 2234,

Alice Springs, NT 0871,

Australia;

srinib75@hotmail.com

Accepted 15 August 2001

\begin{abstract}
Objective: To study the postnatal changes in the plasma concentrations of fat soluble antioxidant vitamins and malondialdehyde (MDA) in mothers and their newborns and their relation to smoking.

Design: Prospective cohort study.

Setting: Tertiary perinatal centre.

Subjects: Eighteen non-smoking and 14 smoking mothers and 33 infants.

Main outcome measures: Plasma concentrations of vitamins $E, A$, and $\beta$-carotene and MDA were measured in mothers and infants at delivery and on day 4 post partum.

Results: Neonatal plasma levels of vitamins $E, A$, and $\beta$-carotene were significantly lower than maternal levels both at delivery and on day 4 in both groups. There was a significant postnatal increase in plasma vitamin $\mathrm{E}$ levels in smoking mothers and neonates of both groups. A significant postnatal increase in maternal, but not neonatal, plasma vitamin A was noted in both groups. Cord plasma vita$\min E$ levels were significantly lower in infants of smoking mothers (mean $4.7 v 6.5 \mu \mathrm{mol} / \mathrm{l}, \mathrm{p}=0.041$ ). Plasma MDA was paradoxically lower in smoking mothers at delivery $(3.19 \vee 4.01 \mathrm{\mu mol} / \mathrm{l}, p=0.03)$ and on day $4(1.37 \vee 3.29 \mu \mathrm{mol} / \mathrm{l}, \mathrm{p}=0.005)$ and in infants of the smoking group on day $4(2.18$ $v 3.12 \mu \mathrm{mol} / \mathrm{l}, \mathrm{p}=0.014$ ). Also, there was a significant postnatal fall in plasma MDA levels on day 4 in mothers and infants in the smoking group.

Conclusions: The postnatal changes in plasma vitamin $E$ were more pronounced in the smoking group. The postnatal changes in plasma vitamins $A$ and $\beta$-carotene were similar in both groups. The rapid decline in plasma MDA in smoking mothers and their infants suggests withdrawal of oxidative stress from smoking around delivery. This coincided with the increase in plasma vitamin $\mathrm{E}$.
\end{abstract}

n recent years there has been a shift in research emphasis on smoking from men to women with increasing similarity of smoking habits between the two sexes. About $20 \%$ of Australian women are estimated to smoke in pregnancy. ${ }^{2}$ With 250000 births per year in Australia, this translates to about 50000 pregnant women who are smoking every year.

Cigarette smoking has been suggested as a source of oxidant stress in pregnant women and newborns exposed in utero. This is based on indirect evidence from studies that showed that the nutritional status of smokers may be compromised by an inadequate diet, and that smoking is associated with a lower intake of antioxidants. ${ }^{3-6}$ It has been reported that antioxidant vitamins $\mathrm{C}$ and $\mathrm{E}$ and $\beta$-carotene are at suboptimal concentrations in the tissues of smokers. ${ }^{4-6}$ The deficiency of these antioxidant vitamins may promote peroxidation events leading to the release of oxygen free radicals. Malondialdehyde (MDA) is a highly reactive metabolite of free radical induced lipid peroxide and is a commonly used index of lipid peroxide. Plasma MDA is normally raised in pregnancy and delivery. ${ }^{7}$

There are no data about the changes in the plasma antioxidant vitamin status of the newborn infant at delivery and in the immediate neonatal period particularly in relation to maternal smoking. The main objective of this study was to evaluate the changes in plasma concentrations of antioxidant vitamins, including vitamins $A, E$, and $\beta$-carotene and MDA, in mothers and neonates during the immediate postnatal period. We further hypothesised that the pregnant women who smoked and their infants would have lower plasma antioxidant vitamins at delivery than the non-smoking group.

\section{METHODS}

A prospective cohort study was conducted at Kirwan Hospital for Women, a major tertiary perinatal regional centre in North
Queensland. Mothers were recruited over two and half months. Attempts were made to recruit as many smoking mothers as possible when presented for delivery. A comparable group of non-smoking mothers and infants were recruited randomly over the same range of gestational age. The institutional ethics committee approved the study protocol. Prior informed consent was obtained. Women with any pregnancy related or other long standing illnesses that could affect their nutritional status and/or women taking antioxidant vitamin supplements were excluded from the study.

A history of smoking was obtained by direct questioning at presentation to the delivery suite. Smokers were defined as women who reported smoking up to the date of delivery, regardless of the reported number of cigarettes smoked a day. Non-smokers were women who had never smoked either before or during pregnancy.

\section{Plasma analysis}

Venous blood samples were collected from women on the day of delivery. Cord blood was obtained immediately post partum from the umbilical vein after clamping of the cord. A second set of blood samples was collected from mothers and neonates when the infant was due for a routine newborn screening test on day 4 of life. Blood samples were collected in EDTA specimen tubes. Samples were spun immediately, and plasma was stored at $-70^{\circ} \mathrm{C}$ in liquid nitrogen. Plasma $\beta$-carotene, vitamins A (retinol) and E ( $\alpha$-tocopherol), and MDA levels were measured using high performance liquid chromatography analysis in batches at the Department of Clinical Chemistry, Prince of Wales Hospital, Sydney. ${ }^{8}$

Abbreviations: MDA, malondialdehyde. 
Table 1 Maternal characteristics and dietary intake

\begin{tabular}{|c|c|c|c|}
\hline & Non-smokers $(n=18)$ & Smokers $(n=14)$ & $p$ Value \\
\hline Age (years) & $26(16-36)$ & $24(16-43)$ & 0.282 \\
\hline Primigravida & $8(44 \%)$ & $7(50 \%)$ & 0.80 \\
\hline Indigenous women & $2(11 \%)$ & $5(36 \%)$ & 0.09 \\
\hline Weight at $1 \mathrm{st}$ trimester $(\mathrm{kg})$ & $73.6(51-106)$ & $79(61-110)$ & 0.321 \\
\hline Height $(\mathrm{cm})$ & $165(146-175)$ & $162(152-173)$ & 0.240 \\
\hline \multicolumn{4}{|l|}{ Antenatal illnesses } \\
\hline Nil & 14 (78\%) & 10 (71\%) & 1.00 \\
\hline $\mathrm{APH}$ & $1(5 \%)$ & $1(7 \%)$ & 1.00 \\
\hline Premature labour & $2(11 \%)$ & $3(21 \%)$ & 1.00 \\
\hline Mild PIH & $1(5 \%)$ & 0 & 1.00 \\
\hline Antenatal steroids given & $3(17 \%)$ & $2(14 \%)$ & 1.00 \\
\hline Normal vaginal delivery & $10(56 \%)$ & $9(64 \%)$ & 0.851 \\
\hline \multicolumn{4}{|l|}{ Dietary intake } \\
\hline Energy (M/day) & $9.6(0.6)$ & $3.4(0.6)$ & $0.019 *$ \\
\hline Proteins (g/day) & $99.6(6.8)$ & $106.5(4.1)$ & 0.425 \\
\hline Fat (g/day) & $94.9(8.0)$ & $112.7(7.7)$ & 0.128 \\
\hline Carbohydrate (g/day) & $266.7(19.4)$ & $349.1(29.6)$ & $0.022 *$ \\
\hline Total vitamin A eqiv ( $\mu \mathrm{g} /$ day) & $1129.5(94.6)$ & $1253.6(116)$ & 0.627 \\
\hline Vitamin C (mg/day) & $201.6(27.2)$ & $261.4(56.1)$ & 0.312 \\
\hline
\end{tabular}

\section{Dietary assessment}

A questionnaire based on the design described by Morgan et $a l^{10}$ was used to obtain the dietary history of the women. The questionnaire was administered by the dietitian once to each participant. The questionnaire was coded and analysed by the same investigator. The intake of each food item was computed by multiplying the number of times a week it was consumed by its standard portion size in accordance with the hospital dietary questionnaire manual. The average daily intake of energy, protein, fat, carbohydrate, vitamin C, and vitamin A was calculated using the Food works Australian version 2.04 (Xyris software Pty Ltd, Australia). Analysis of vitamin E intake was not available in this software.

Results were analysed using the Fisher exact test, Student's $t$ test, or the Mann-Whitney rank sum test where appropriate. The paired $t$ test was used for comparisons of two serial samples within the group or between mother and infant pairs.

\section{RESULTS}

Thirty two pregnant women were recruited: 14 were smokers of 30-41 weeks gestation and 18 were non-smokers of 31-42 weeks gestation. One smoking mother gave birth to a pair of dizygotic twin. The twins were taken as two independent cases in the infant comparisons and in the paired analyses of mother-infant differences. Table 1 shows the characteristics of the women in the study. No significant difference was noted between the two groups in age, parity, ethnicity, weight, and height at first hospital visit, antenatal illnesses, administration of antenatal steroids, and type of delivery. The mean (range) self reported number of cigarettes smoked daily by smoking mothers was $12.1(5-20)$. The mean daily energy intake was significantly higher in smoking mothers ( $11.7 \vee 9.6 \mathrm{MJ} /$ day, $\mathrm{p}=0.019$ ). This was mainly due to a higher daily carbohydrate intake $(349.1 \mathrm{~g} /$ day $v 266.7 \mathrm{~g} /$ day, $\mathrm{p}=0.022$ ).

Table 2 summarises the neonatal characteristics of the study population. There was no significant difference between the two groups of infants in birth weight, sex, gestation, incidence of neonatal illnesses, and the need for supplemental oxygen therapy. None of them had Apgar scores less than 4 and/or 7 at one and five minutes, and no infant needed $\mathrm{FIO}_{2}$ greater than 0.35 . More boys were born to the smoking mothers, but the difference was not statistically significant.

\section{Plasma vitamins}

Tables 3 and 4 show the postnatal changes in plasma levels of vitamins $\mathrm{E}, \mathrm{A}$, and $\beta$-carotene in both the non-smoking and smoking groups. Plasma levels of these vitamins in neonates at delivery and on day 4 were significantly lower than in their mothers in both the non-smoking and smoking groups. Except in non-smoking mothers, there was a significant increase in plasma vitamin $\mathrm{E}$ on day 4 compared with at delivery in mothers and infants. Even in non-smoking mothers, there was a trend toward higher levels of vitamin E on day 4. There was a significant increase in maternal plasma vitamin A on day 4 in both groups, but the changes in plasma vitamin $\mathrm{A}$ in infants were not significant. No significant postnatal changes were noted in plasma $\beta$-carotene in any of the groups.

When the mean values were compared between the non-smoking and smoking groups, plasma vitamin E concentrations of smoking mothers at delivery and on day 4 were not different from those of non-smoking mothers. However, mean cord plasma vitamin E concentrations of the infants in the smoking group were significantly lower than in infants of the non-smoking group $(4.7 v 6.52 \mu \mathrm{mol} / \mathrm{l}, \mathrm{p}=0.041)$. On day 4 , both increased to a similar level and the difference was not significant. Plasma levels of vitamin A and $\beta$-carotene were not significantly different between the two groups either at delivery or on day 4.

\section{Plasma MDA}

Table 5 shows the results. There was a significant fall in mean plasma MDA from birth to day 4 in mothers and infants of the

\begin{tabular}{|c|c|c|}
\hline & $\begin{array}{l}\text { Non-smokers } \\
(n=18)\end{array}$ & $\begin{array}{l}\text { Smokers } \\
(n=15)\end{array}$ \\
\hline Mean (range) birth weight (g) & $\begin{array}{l}3160.5 \\
(1440-4230)\end{array}$ & $\begin{array}{l}2898 \\
(1555-3820)\end{array}$ \\
\hline Male & $8(44 \%)$ & $10(67 \%)$ \\
\hline $\begin{array}{l}\text { Median (range) gestation } \\
\text { (weeks) }\end{array}$ & $40(31-42)$ & $38(30-41)$ \\
\hline $\begin{array}{l}\text { No babies on } \mathrm{O}_{2} \\
\text { supplementation }\end{array}$ & $1(5 \%)$ & $2(13 \%)$ \\
\hline \multicolumn{3}{|l|}{ Neonatal illnesses } \\
\hline Nil & $14(78 \%)$ & $11(73 \%)$ \\
\hline Meconium aspiration & 0 & $1(7 \%)$ \\
\hline Hypoglycaemia & 0 & $2(13 \%)$ \\
\hline $\begin{array}{l}\text { Transient tachypnoea of } \\
\text { newborn }\end{array}$ & $1(5 \%)$ & 0 \\
\hline
\end{tabular}


Table 3 Maternal and neonatal plasma vitamin E levels

\begin{tabular}{|c|c|c|c|c|c|c|c|c|}
\hline & \multicolumn{4}{|c|}{ Non-smoking group } & \multicolumn{4}{|l|}{ Smoking group } \\
\hline & Delivery & Day 4 & MD $(95 \% \mathrm{Cl})$ & $\mathrm{p}$ Value & Delivery & Day 4 & MD $(95 \% \mathrm{Cl})$ & $\mathrm{p}$ Value \\
\hline Mother & $34.47(2.54)$ & $39.76(2.83)$ & $-5.29(-12.17$ to 3.79$)$ & 0.17 & $30.2(1.57)$ & 38 (1.72) & $-7.8(-14.52$ to -1.6$)$ & 0.018 \\
\hline Infant & $6.52(0.66)$ & $20.88(3.63)$ & $-14.36(-22.16$ to -6.42$)$ & $<0.001$ & $4.7(0.73)^{*}$ & $21.1(3.8)$ & $-16.4(-25.5$ to -7.1$)$ & 0.002 \\
\hline & 27.95 & 18.88 & & & 25.5 & 16.9 & & \\
\hline $95 \% \mathrm{Cl}$ & 23.64 to 33.69 & 9.75 to 28.01 & & & 22.2 to 29.48 & 8 to 25.65 & & \\
\hline $\mathrm{p}$ Value & $<0.001$ & $<0.001$ & & & $<0.001$ & 0.001 & & \\
\hline
\end{tabular}

Plasma levels in $\mu \mathrm{mol} / \mathrm{I}$. Mean (SEM) values, mean difference (MD) with $95 \%$ confidence intervals, and $p$ values are shown.

${ }^{*} p=0.041$, between infants of smoking and non-smoking groups at birth.

Table 4 Maternal and neonatal plasma $\beta$-carotene and vitamin A levels

\begin{tabular}{|c|c|c|c|c|c|c|c|c|}
\hline & \multicolumn{4}{|c|}{ Non-smoking group } & \multicolumn{4}{|l|}{ Smoking group } \\
\hline & Delivery & Day 4 & MD $(95 \% \mathrm{Cl})$ & p Value & Delivery & Day 4 & MD (95\% Cl) & $\mathrm{p}$ Value \\
\hline \multicolumn{9}{|l|}{$\beta$-Carotene } \\
\hline Mother & $0.49(0.06)$ & $0.38(0.06)$ & $0.11(-0.06$ to 0.25$)$ & 0.223 & $0.33(0.04)$ & $0.31(0.03)$ & $0.02(-0.07$ to 0.05$)$ & 1.0 \\
\hline Infant & $0.09(0.005)$ & $0.11(0.01)$ & $-0.02(-0.05$ to 0.01$)$ & 0.50 & $0.09(0.001)$ & $0.09(0.004)$ & 0 & 0.75 \\
\hline$M D$ & 0.3 & 0.27 & & & 0.24 & 0.22 & & \\
\hline $95 \% \mathrm{Cl}$ & & & & & 0.14 to 0.29 & 0.14 to 0.27 & & \\
\hline$p$ Value & $<0.001$ & $<0.001$ & & & $<0.001$ & $<0.001$ & & \\
\hline \multicolumn{9}{|l|}{ Vitamin A } \\
\hline Mother & $0.97(0.11)$ & $2.08(0.16)$ & $-1.11(-1.59$ to -0.62$)$ & $<0.001$ & $1.01(0.09)$ & $1.82(0.11)$ & $-0.81(-1.08$ to -0.57$)$ & $<0.001$ \\
\hline Infant & $0.67(0.05)$ & $0.72(0.05)$ & $-0.05(-0.22$ to 0.08$)$ & 0.346 & $0.81(0.06)$ & $0.65(0.11)$ & $0.16(-0.13$ to 0.39$)$ & 0.29 \\
\hline$M D$ & 0.30 & 1.36 & & & 0.2 & 1.17 & & \\
\hline $95 \% \mathrm{Cl}$ & 0.03 to 0.61 & 1.03 to 1.69 & & & -0.03 to 0.37 & 0.82 to 1.53 & & \\
\hline $\mathrm{p}$ Value & 0.038 & $<0.001$ & & & 0.04 & $<0.001$ & & \\
\hline
\end{tabular}

Plasma levels in $\mu \mathrm{mol} / \mathrm{I}$. Mean (SEM) values, mean difference (MD) with $95 \%$ confidence intervals, and $p$ values are shown.

Table 5 Maternal and neonatal plasma malondialdehyde levels

\begin{tabular}{|c|c|c|c|c|c|c|c|c|}
\hline & \multicolumn{4}{|c|}{ Non-smoking group } & \multicolumn{4}{|l|}{ Smoking group } \\
\hline & Delivery & Day 4 & $\mathrm{MD}(95 \% \mathrm{Cl})$ & $p$ Value & Delivery & Day 4 & MD $(95 \% \mathrm{Cl})$ & $p$ Value \\
\hline $\begin{array}{l}\text { Mother } \\
\text { Infant } \\
\mathrm{MD} \\
95 \% \mathrm{Cl} \\
\mathrm{p} \text { Value }\end{array}$ & $\begin{array}{l}4.01(0.43) \\
3.16(0.28) \\
0.85 \\
0.11 \text { to } 1.76 \\
0.059\end{array}$ & $\begin{array}{l}3.29(0.53) \\
3.12(0.23) \\
0.17 \\
-1.05 \text { to } 1.39 \\
0.77\end{array}$ & $\begin{array}{l}0.72(-1.14 \text { to } 2.53) \\
0.04(-0.79 \text { to } 0.58)\end{array}$ & $\begin{array}{l}0.442 \\
0.75\end{array}$ & $\begin{array}{l}3.19(0.13)^{*} \\
3.41(0.56) \\
-0.22 \\
-1.47 \text { to } 1.04 \\
0.54\end{array}$ & $\begin{array}{l}1.37(0.26) \dagger \\
2.18(0.27) \ddagger \\
-0.81 \\
-1.57 \text { to }-0.04 \\
0.04\end{array}$ & $\begin{array}{l}1.82 \text { (1.36 to } 2.30) \\
1.23(1.05 \text { to } 2.7)\end{array}$ & $\begin{array}{l}<0.001 \\
0.04\end{array}$ \\
\hline
\end{tabular}

Plasma levels in umol/I. Mean (SEM) values, mean difference (MD) with $95 \%$ confidence intervals, and $p$ values are shown.

${ }^{*} p<0.03$, between non-smoking and smoking mothers at delivery; $\nmid p<0.005$, between non-smoking and smoking mothers on day $4 ; \ddagger p<0.014$, between infants of smoking and non-smoking mothers on day 4.

smoking group. In non-smoking mothers, the postnatal fall in plasma MDA was small and not significant (mean difference of 0.72 in non-smokers $v 1.82$ in smokers). Similarly, infants of the non-smoking group showed a small and non-significant postnatal fall in MDA in contrast with infants of the smoking group (mean difference of 0.04 in the non-smoking group $v$ 1.23 in the smoking group).

MDA levels were paradoxically lower in mothers who smoked than those who did not, both at delivery and on day 4 (3.19 $v 4.01 \mu \mathrm{mol} / \mathrm{l}$ at delivery, $\mathrm{p}=0.03 ; 1.37 \vee 3.29 \mu \mathrm{mol} / \mathrm{l}$ on day $4, p=0.005)$. In infants, mean cord plasma MDA levels were similar in both groups. However, on day 4, the plasma MDA was significantly lower in infants in the smoking group $(2.18 \vee 3.12 \mu \mathrm{mol} / \mathrm{l}, \mathrm{p}=0.014)$.

As there were more boys in the smoking group, we repeated the analyses comparing the two sexes; no statistically significant difference was noted in any of the assays.

\section{DISCUSSION}

To our knowledge, this is the first study to investigate the differences in postnatal changes in the plasma levels of fat solu- ble antioxidant vitamins and MDA in smoking and nonsmoking mothers and their neonates. The concentrations of vitamins $\mathrm{A}$ and $\mathrm{E}$ and $\beta$-carotene in maternal and cord plasma at delivery in our population were comparable to those in previous studies. ${ }^{11}{ }^{12}$ Cord plasma, in general, contained significantly lower levels of vitamins $\mathrm{A}$ and $\mathrm{E}$ and $\beta$-carotene than maternal plasma. Similar findings have been reported in previous studies. ${ }^{11-15}$ This is thought to be due to the low levels of circulating lipophilic substances in cord plasma, which limits the transport capacity of cord plasma for tocopherols and carotenoids. ${ }^{14}{ }^{15}$ Oostenbrug et $a l_{,}{ }^{12}$ however, showed that umbilical cord levels of tocopherols and carotenoids are lower than maternal levels, even after correction for the lower polyunsaturated fatty acid content of plasma phospholipids in neonates.

We found a significant increase in plasma vitamin $\mathrm{E}$ concentration from delivery to day 4 in smoking mothers and neonates of both groups. A similar, but statistically not significant, trend was noted in non-smoking mothers. The increase in maternal vitamin A was much higher, but no significant changes were noted in infants. $\beta$-Carotene also showed no 
significant changes in either group. The fact that the plasma levels of these fat soluble vitamins increased at different rates on day 4 in mothers and neonates suggests a more complex physiology than their interrelationship with the phospholipid content of plasma.

Vitamin E is by far the most abundant lipid soluble antioxidant in humans and belongs to the first line of antioxidant defence against lipid soluble peroxyl radicals. ${ }^{16}{ }^{17}$ It is known that the circulating markers of oxidative stress such as MDA are normally increased in pregnancy. ${ }^{7}$ It has also been clearly shown in vitro that endogenous antioxidants in the body are consumed by lipid peroxidation, and with increasing lipid hydroperoxides, there is a decrease in vitamin E concentration in plasma. ${ }^{16}{ }^{17}$ Our finding of significantly lower plasma vitamin E levels at delivery than in the immediate postnatal period in both mothers and neonates suggests increased oxidative stress at the time of delivery. The increase in plasma vitamin $\mathrm{E}$ levels on day 4 is probably due to cessation of delivery induced oxidative stress. The same mechanism can probably explain similar increases in maternal plasma vitamin A on day 4 . The postnatal changes in plasma vitamin $\mathrm{E}$ were more pronounced in smokers than in non-smokers. Also, cord plasma vitamin $\mathrm{E}$ in infants of the smoking group was significantly lower than in infants of the non-smoking group. These findings suggest an important role for vitamin $\mathrm{E}$ in providing antioxidant defence in the smoking group. However, no such trend was noted with either vitamin $\mathrm{A}$ or $\beta$-carotene in our study.

Ortega et $a l^{4}$ showed significantly lower vitamin E concentrations in mature milk of smoking mothers. We showed significantly lower cord plasma vitamin $\mathrm{E}$ concentrations in infants of mothers who smoked than in infants in the non-smoking group. Kiely et $a l^{13}$ examined the effects of maternal smoking on plasma vitamin E levels of the neonates and could not show any significant difference in cord plasma vitamin $\mathrm{E}$ concentration between the smoking and nonsmoking groups. This could be because they categorised their study population on the basis of smoking habits early in pregnancy. Also, a number of the smokers reported "cutting down" the consumption of cigarettes when they became pregnant. It is consistent with the smoking habits of pregnant women in Australia, many of whom either stop or reduce the amount of smoking during pregnancy. ${ }^{1}$ We categorised our study population on the basis of smoking habits at the time of delivery, and we were able to show a significant difference in cord plasma vitamin E concentrations between the two groups. Measurement of plasma cotinine as an objective estimate of smoking would have further strengthened our findings.

In this context, it is important to note the role of other antioxidant vitamins, particularly vitamin C, in providing antioxidative defence in the body. Whereas vitamin $\mathrm{E}$ is an important radical scavenging vitamin of the lipid soluble environment, vitamin $\mathrm{C}$, together with glutathione, is a major antioxidant in the water soluble compartment. ${ }^{18}$ Active transport across the placenta results in much higher plasma vitamin $\mathrm{C}$ concentrations at birth than in adult life. Whether high concentrations of vitamin $\mathrm{C}$ are always beneficial to the newborn is questionable, as it has been suggested that it can also act as a pro-oxidant in newborns, reducing non-protein-bound ferric iron $\left(\mathrm{Fe}^{3+}\right)$ to the dangerous ferrous $\left(\mathrm{Fe}^{2+}\right)$ form. ${ }^{19}$ We could not measure plasma vitamin $\mathrm{C}$ for technical reasons, but vitamin $\mathrm{C}$ concentrations in mature milk of smoking mothers was found to be low. ${ }^{5}$

In addition to epidemiological evidence indicating the adverse effects of smoking on pregnant women and their babies, there is mounting biochemical evidence suggesting that cigarette smoking is a source of oxidant stress in pregnant women and their newborns..$^{2-520}$ Schwartz et $a l^{3}$ used the breath ethane test as an index of oxidant stress in newborn infants in their study. The breath ethane of the infants whose mothers smoked was higher than that of infants whose mothers did not smoke. We used plasma MDA as a marker of lipid peroxidation; it is one of the most commonly used indicators of lipid peroxidation. Plasma MDA levels may vary from day to day within the subject and more importantly it can be acutely altered by cigarette smoke within hours. ${ }^{21}$ In our study, MDA levels showed no significant difference in non-smoking mothers and their infants. In the smoking mothers, there was a $57 \%$ fall in plasma MDA levels by day 4 and this was accompanied by a $36 \%$ fall in their infants. This coincided with the simultaneous increase in plasma vitamin $\mathrm{E}$ concentration in smoking mothers and their neonates. These findings may suggest that oxidative stress is alleviated after delivery, coinciding with temporary cessation/reduction of smoking by mothers during the immediate postnatal period and/or an upregulated endogenous antioxidant system caused by chronic oxidative stress from smoking. A more thorough history of smoking habits during the immediate postnatal period and the measurement of plasma endogenous antioxidant enzymes would help to clarify our findings.

Because of the rapid metabolism and wide variation of MDA, Rogers et al ${ }^{22}$ proposed that plasma organic hydroperoxides would be a better marker of free oxygen radical activity in the fetus. Nonetheless, the observation of diminishing oxidative stress as related to maternal smoking should still be considered valid.

Our observations are unlikely to be influenced by the nutritional status of the pregnant mothers. Muscati et $a^{23}$ found, despite higher energy intake, smoking was associated with lower maternal weight gain and infant birth weight. Maternal weight at first trimester and infant birth weight were no different in the smoking and non-smoking groups. As in the study of Muscati et al, the women in our study who smoked had a higher energy intake than the control group. Reasons for this nutritional difference were not clear. Finally, there have been studies on the efficacy of either vitamin $\mathrm{E}$ and/or a mixture of antioxidant formulation in mitigating the effects of oxidative stress induced by smoking with mixed results. ${ }^{24}{ }^{25}$ Further studies are needed to evaluate the effects of maternal supplementation of antioxidants on the peroxidation activity of the fetus and the neonate.

\section{Authors' affiliations}

S Bolisetty, T H H G Koh, D Watson, R Montgomery, J Whitehall, Kirwan Hospital For Women, Townsville, Queensland, Australia D Naidoo, K Lui, University of New South Wales, Sydney, NSW, Australia

\section{REFERENCES}

1 Counsilman JJ, Mackay EV. Smoking habits of pregnant women in Brisbane, Australia. Aust N Z J Obstet Gynaecol 1985:25:244-7.

2 Wong PPL, Bauman A. How well does epidemiological evidence hold for the relationship between smoking and adverse obstetric outcomes in New South Wales. Aust N Z J Obstet Gynaecol 1997;37: 168-73.

3 Schwarz KB, Cox JM, Sharma S, et al. Prooxidant effects of maternal smoking and formula in newborn infants. J Pediatr Gastroenterol Nutr 1997;24:68-74

4 Ortega RM, Lopez-Sobaler AM, Martinez RM, et al. Influence of smoking on vitamin $\mathrm{E}$ status during the third trimester of pregnancy and on breast-milk tocopherol concentrations in Spanish women. Am J Clin Nutr 1998;68:662-7.

5 Ortega RM, Lopez-Sobaler AM, Quintas ME, et al. The influence of smoking on vitamin $C$ status during the third trimester of pregnancy and on vitamin C levels in maternal milk. J Am Coll Nutr 1998;17:379-84.

6 Moji H, Murata T, Morinobu T, et al. Plasma levels of retinol, retinol-binding protein, all-trans beta-carotene and cryptoxanthin in low birth weight infants. J Nutr Sci Vitaminol 1995;41:595-606.

7 Morris JM, Gopaul NK, Endresen M, et al. Circulating markers of oxidative stress are raised in normal pregnancy and pre-eclampsia. $\mathrm{Br} J$ Obstet Gynaecol 1998:105:1 195-9.

8 Catignani GL, Bieri JG. Simultaneous determination of retinol and alpha-tocopherol in serum or plasma by liquid chromatography. Clin Chem 1983;29:708-12.

9 Young IS, Trimble ER. Measurement of malondialdehyde in plasma by high performance liquid chromatography with fluorimetric detection. Ann Clin Biochem 1991;28:504-8. 
10 Morgan RW, Jain M, Miller AB, et al. A comparison of dietary methods in epidemiologic studies. Am J Epidemiol 1978; 107:488-98.

11 Yeum KJ, Ferland G, Patry J, et al. Relationship of plasma carotenoids, retinal and tocopherols in mothers and newborn infants. J Am Coll Nutr 1998;17:442-7.

12 Oostenbrug GS, Mensink RP, Al MD, et al. Maternal and neonatal plasma antioxidant levels in normal pregnancy, and the relationship with fatty acid unsaturation. Br J Nutr 1998;80:67-73.

13 Kiely M, Cogan P, Kearney PJ, et al. Relationship between smoking, dietary intakes and plasma levels of vitamin $E$ and $\beta$-carotene in matched maternal-cord pairs. Int J Vitam Nutr Res 1999;69:262-7.

14 Hågå P, Ek J, Kran S. Plasma tocopherol levels and vitamin $\mathrm{E} /$ beta-lipoprotein relationships during pregnancy and in cord blood. Am J Clin Nutr 1982;36:1200-4.

15 Martinez FE, Goncalves AL, Jorge SM, et al. Vitamin E in placental blood and its interrelationship to maternal and newborn levels of vitamin E. J Pediatr 1981;99:298-300.

16 Frei B. Reactive oxygen species and antioxidant vitamins: mechanisms of action. Am J Med 1994;97(suppl 3A):5S-13S.

17 Frei B, Stocker R, Ames BN. Antioxidant defenses and lipid peroxidation in human blood plasma. Proc Natl Acad Sci USA 1988;85:9748-52.

18 Bohles H. Antioxidant vitamins in prematurely and maturely born infants. Int J Vitam Nutr Res 1997;67:321-8.
19 van Zoeren-Grobben D, Lindeman JH, Houdkamp E, et al. Postnatal changes in plasma chain-breaking antioxidants in healthy preterm infants fed formula and/or human milk. Am J Clin Nutr 1994;60:900-6.

20 Castles A Adams EK, Melvin CL, et al. Effects of smoking during pregnancy. Five meta-analyses. Am J Prev Med 1999;16:208-15.

21 Nielsen F, Mikkelsen BB, Nielsen JB, et al. Plasma malondialdehyde as biomarker for oxidative stress: reference interval and effects of life-style factors. Clin Chem 1997;43:1209-14.

22 Rogers MS, Wang W, Mongelli M, et al. Lipid peroxidation in cord blood at birth: a marker of fetal hypoxia during labour. Gynecol Obstet Invest 1997:44:229-33.

23 Muscati SK, Koski KG, Gray-Donald K. Increased intake in pregnant smokers does not prevent human fetal growth retardation. J Nutr 1996; 126:2984-9.

24 Surmen-Gur E, Ozturk E, Gur H, et al. Effect of vitamin E supplementation on post-exercise plasma lipid peroxidation and blood antioxidant status in smokers: with special reference to haemoconcentration effect. Eur J Appl Physiol 1999;79:472-8.

25 Howard DJ, Ota RB, Briggs LA, et al. Oxidative stress induced by environmental tobacco smoke in the workplace is mitigated by antioxidant supplementation. Cancer Epidemiol Biomarkers Prev 1998;7:981-8. 